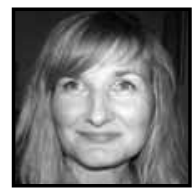

\title{
Commentary
}

\section{A Portrait of the Creative Process in Children's Learning}

\author{
Zenia Dusaniwsky, St. George's Elementary School
}

\begin{abstract}
In this filmed interview, Zenia Dusaniwsky describes her first teaching assignment in South America over 20 years ago and how she eventually became the art teacher at St. George's Elementary School in Montreal. She believes that all children can learn, but not necessarily at the same pace or in the same way. She stresses it is important to "highlight mistakes and failures...not as an endpoint but as part of the process." Moreover, she feels that creativity is as critical as literacy in fostering the overall development of students and their ability to take on future life challenges. She concludes by presenting some of her students' creative art projects.
\end{abstract}

\section{Can you start off by telling us how you decided to become an art teacher?}

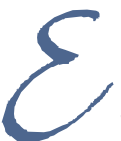

ssentially the decision fell into my lap, so to speak, as a church bulletin. I graduated in 1990 and at the time there were not a lot of jobs available in Montreal. I came across a posting for a job teaching in South America. I knew very little about South America and I knew even less about teaching art but being young and adventurous I was game to take on the challenge. So I went and my teaching load at that time was to do the elementary / middle school art as well as middle school science, computers, high school gym...so I had a little bit of everything. I had no formal training in art at that time. In fact, I hadn't done any art myself, probably since my elementary school experience and so I essentially flew by the seat of my pants and had real joy, pure enjoyment in terms of engaging the students for the pleasure of creating art. But that's essentially where it stayed for those first couple of years. 
Upon returning from South America I went back and actually did a Certificate in teaching Art Education so that I would have a background in terms of techniques and strategies and a little bit more of a formal approach. When I resumed teaching in Montreal I not only had the opportunity to keep the pleasure aspect of creating going, but also I had little bit more to offer the students in terms of the techniques and strategies that they could apply in their creations.

\section{How did you end up in your position at St. George's?}

I originally started here as a research assistant and I retained the position of a grade five homeroom teacher and then I proceeded to take over the grade three homeroom teacher position whereby I taught English Language Arts, Mathematics, and Social Studies... and I did incorporate a lot of art into the curriculum. In the Language Arts there was a lot of art integrated with the writers' sketch-journals that were used as the art always served as a springboard for the writing. I also had students create self-portraits-each year they did at least three. I thought it was a wonderful exercise for them to take a moment to reflect upon how they saw themselves at that particular moment in time. Not to mention for nostalgic purposes, there are students that l've met many years later who still have those portraits framed [laughter]. I taught as a homeroom teacher for 12 years and then I left on maternity leave and this position opened up and I joyfully jumped at it. Coming back to art with more maturity as a teacher enabled me to not only keep the pleasure of creating art and then add the techniques, but I also had a sense of how I needed to address the bigger concepts and the bigger picture of "Why art? Why is it that we were doing what we were doing?" It was no longer just a series of cute activities for the pleasure of doing a cute activity. It's growing in depth in terms of my experience of developing as a professional.

\section{What are your basic beliefs about education generally, and art more specifically?}

I think that learning is life. I think that every incident that you're exposed to, every person that you meet, every experience that you have is an opportunity to learn. Inasmuch as I have the title and the role of a teacher, I think that the students have a lot to teach me as well. As a result, I believe that all children are capable of learning - I think not necessarily at the same time or in the same way. They should be given the time that they need to learn and offered diverse approaches to learning. All children like to learn, that they are "wonder addicts," and that they are innately curious. I believe that parents are crucial partners in a child's learning... as well as the 
culture and community in which the child is raised....ALL these influence their education. I think that literacy is essential, and by literacy I don't mean just reading and writing; visual literacy, media literacy as well as mathematics literacy and science literacy are very important. I think creativity is as important as literacy is. I think that success breeds success and that can become addictive. I feel that it's important for children to learn to be independent. At the same time, it's important to teach them the soft skills of working in a team collaboratively. I think that if learning did not occur, that teaching did not occur...so I often think about that when I'm writing reports and I'm evaluating the students, the ones who have had difficulty I think of what may have been lacking in my teaching. Learning is also something that's intrinsically innate in that the learner has to take ownership of what they're learning in order for there not to be a dissociation. It's important to address the purposefulness of what I am teaching so that the students see the big "Why?" and I think that this can then be transferred to other areas.

I believe that art is fundamental in the development of the child in terms of their motor development but also in their social, cognitive, and emotional development. I believe that children prefer a strong and firm boundary when they're learning and when they're creating, but then also knowing that there's a freedom within those parameters. I really believe that art, to a great extent, is about pushing on those limits...it's about pushing those limits and pushing the potential of the creativity within that defined parameter. It's my job to set up a context in which the students can push and then realize the potential of their creativity. I think creativity is innate to everyone as a human being; you have it because you're human. I think that it can be taught, re-taught-it's almost as if we have to remember that we are creative beings and that it can be modelled. I believe that, in terms of art, children's work should be posted in public as much as possible. I believe that children can be inspired. They are easily inspired because things easily awe them. I think, most importantly in art, that there needs to be time: time to play and time for spontaneity. I think it was John Muir that said something to the [effect] that, "play is the exultation of the possible" and as much as possible in the confines of a constrained schedule I think it's important to create time for play and experimentation with a new medium or a new idea. That's the time where children can take risks and they can share their ideas and adapt their ideas. 
Can you give some examples of how teaching art to elementary students has surprised you on occasion and/or taught you something important?

I think one of the difficulties sometimes in art is that because there is a constrained time in a classroom setting, that usually the first idea is the last idea. I am constantly trying to find new ways to make it so that there is more time to play. I think that it's important to highlight mistakes and failures, not as a cul de sac, not as an endpoint but as part of the process. I think it was Einstein that said something to the effect of, "If a person hasn't made a mistake it's because they haven't tried anything new." We're constantly celebrating mistakes, and in art "you really can't make a mistake," I tell the children, and, in fact, it might be the best thing that happened, these wonderful accidents. I think that it's important to give the decision-making and the control as much as possible to the students so that they can really make those choices and take ownership for their learning. And therein there comes a balance: you have this free-play time and this time for just exuberance and play and experimentation and exploration, and then there is that inner critic that gets silenced during this sacred time but then later it needs to come to the fore and really suss out and make decisions based on the ideas that have been developed to really come to an end of that creative process. I think there's that synergy of opposites that occurs and there's an important need to also leave the time to reflect on the process. My job, in all of that, I feel like I'm an enabler [laughter] and what I do is I am enabling by creating that structure for all of that to happen... and so the children are playing, and they have the pleasure of creating and they're learning techniques, it might be techniques with different media, and they're learning the creative process which I try to make as explicit as possible, and they're learning the strategies and the big concepts-and I get paid for that, and that's quite extraordinary.

I think that one example of "the importance of play" that sticks out in my mind-because it was a recent example - is when I was working with a student with Down syndrome. It was an ultimate pleasure, privilege for me that on occasion I would have an opportunity to work with her one on one. And inasmuch as I would set up the creative situation for her, I then took the opportunity to follow her lead and see what she would do. I mirrored her approach, her use of materials. Her process was nowhere near my process...so if she would make a mark or place a colour in a certain place or do some gesture, it would make no sense to me but I would follow along. I think the beauty of that was seeing when there is no inner critic, that all things are possible. The trick there was teaching her how to find the right moment to stop because the sensory would otherwise take over and there was no end in sight [laughter]. I think for the younger children too, kindergarten and grade one, they are so raw and so full 
of delight with just the sensory experience of the materials, that really for them, art is about learning to find the right moment to stop. A lot of the organization of the program is about creating and exploring with different media and also learning when to stop... when to stop making marks, and when to stop mixing the colours so it doesn't always become a brown and a grey [laughter].

One of the things that also strikes me is the idea that the best creative work that I have seen over the course of the years that I've been teaching art comes within a structured parameter. You would think that entirely open-ended would produce more astonishing results but I think there's a certain terror and almost a paralysis with ultimate freedom. It makes me think of a story from my childhood of being enclosed in our backyard. We had a big beautiful backyard and I was the youngest on the street and everybody else was at least four years older and the children would often come and pop their bicycles over the fence and then play with me a while and then leave. I was alone in the backyard and I would watch day after day how it is that they crossed over that fence. I was about three years old and one day I figured out how to do it, and I got over to the other side, but they had all taken off on their bikes and left. And I remember that crystallizing moment of being on the other side of the fence and realizing I could go anywhere, I could do anything: the world was entirely open to me-and that terrified me. And I remember calling out to my mother and she opened the gate and I ran back in. I think that's what that structure does for students: it tells them you're allowed to play within this parameter; do whatever, push the limits, you can put a limb over, you can put your head over, you can suspend yourself over...but stay in here. I think that's how the most creative work comes.

I'm also in awe, even at the earliest ages, of how children are able to respond to art. I think one of the things that makes us distinct as human beings is that we can function with symbols and we can communicate through symbols. There's an example in the other room. In grade two I was looking with the students at the work of Mark Rothko and we were talking about how colour speaks. We analyzed his style and the children looked at the fact that it was essentially about fields of colour, and what could you say with colour? And they came up with titles for his pieces and then I put out a time line of his work and I asked them to talk to me about what they saw. Even at six and seven years of age, there was one child who really had me with my mouth hanging open, who was able to essentially read Mark Rothko's life through his work. He talked about Rothko's youth and that his colour choices would have made sense in terms of his youthfulness and exuberance and joy of life having all prospects ahead of him... and how with time the colours became more sombre when perhaps he realized that he was aging and even with the success that he achieved that he wasn't leading 
the type of life that he would have wanted to... This child even inferred that perhaps Rothko died or was close to his death with the colour shift.

The accessibility of the art never ceases to amaze me with the students. They get it; they get it on so many levels. Even the kindergarten class for example: the kindergarten program is structured on "Why art?"That's the underlying question, the undergirding question for the program...so we look at art as a doorway to the imagination...how you can't make a mistake in art... art can address the impossible, things that don't exist... art can address fears that you might have... we look at art as monsters or beasts or mythical creatures. We then went into art as narrative and we looked at how art can tell a story, how images can tell a story, and we looked at the Lascaux cave paintings and they enacted hunting scenes and rituals that may have preceded a hunting scene and then they created their own Lascaux-style paintings. We then looked at art as an opportunity to leave a mark: we want to create something to leave our mark, knowing that we are mortals. In our most recent project we were looking at art as decoration. We were decorating the human body, so the children looked at images of people who decorate themselves throughout the world. We had many images posted including warriors from Papua New Guinea as well as people doing Japanese theatre... and I asked them to group these images and think about why people would decorate themselves. Given that we had done all this work about the hunting, they talked about the fact that the people might disguise themselves to embody the spirit of the animal that they were hunting, or the type of hunter that they would like to be, and then they saw that the warrior aspect was present in the images and they grouped together images that they thought might be warriors wishing to frighten their enemies. Then I asked the students if any of them had parents who decorate themselves or paint their faces, and the students responded, "Yes. You know my mom paints her face." And I had asked, "Do you think it's to scare her enemies?" and "Oh yes," they said [laughter]. Then quickly one of the little girls rectified and said, "No, it's to make herself beautiful." But they get it; they get it on a very innate level. It is something that's primal-it's part of us, it's part of who we are.

That whole accessibility of art and the discussions about art are something that always leave me really energized. And I know that they come away with a sense of art being part of their lives. I remember one student in grade two: I had brought in multiple objects and asked them to tell me what they all had in common. In the end, one of the students said, "So, you mean to tell me everything is art, all of this is art? My teacup is art and my bathroom sink is art and my bedspread is art?" And they walk away with a sense of "it's all art" and then the best part is one of the students had said, "So I'm art too, aren't I? I'm living art." I think that's a gift to think of ourselves as living works of art, something we're constantly and "ongoingly" creating. 
In your opinion, what do you think educators should do to develop creative learners for the 21st century?

I think that given that we're preparing students for a life that we're not familiar with, we are not really sure what lies ahead, I think there are some fundamentals that need to be in place. I think that creative problem solving would be one of those things, definitely critical thinking, the ability to communicate well, the ability to collaborate with others... A lot of jobs in the future will rely heavily on team efforts. Given that the amount of information we have access to at present can be difficult to navigate, we need to prepare our students to deal with information management and to become media savvy and to be digital citizens as well-that's their reality.

I also have a soft spot in my heart for thinking that part of education still has to include teaching things like honour, trust, love, kindness, cooperation, peaceful conflict resolution, ethical economics, understanding power, and things of that nature. But I think creativity is extremely important. We need to have students and people who are going to be able to think unconventionally and to question the herd....and to make decisions and to imagine new scenarios and to then generate new ideas and refine these ideas and produce astonishing innovative work and solutions to problems that we're going to have.

Would you like to share some of your students' artwork with us?

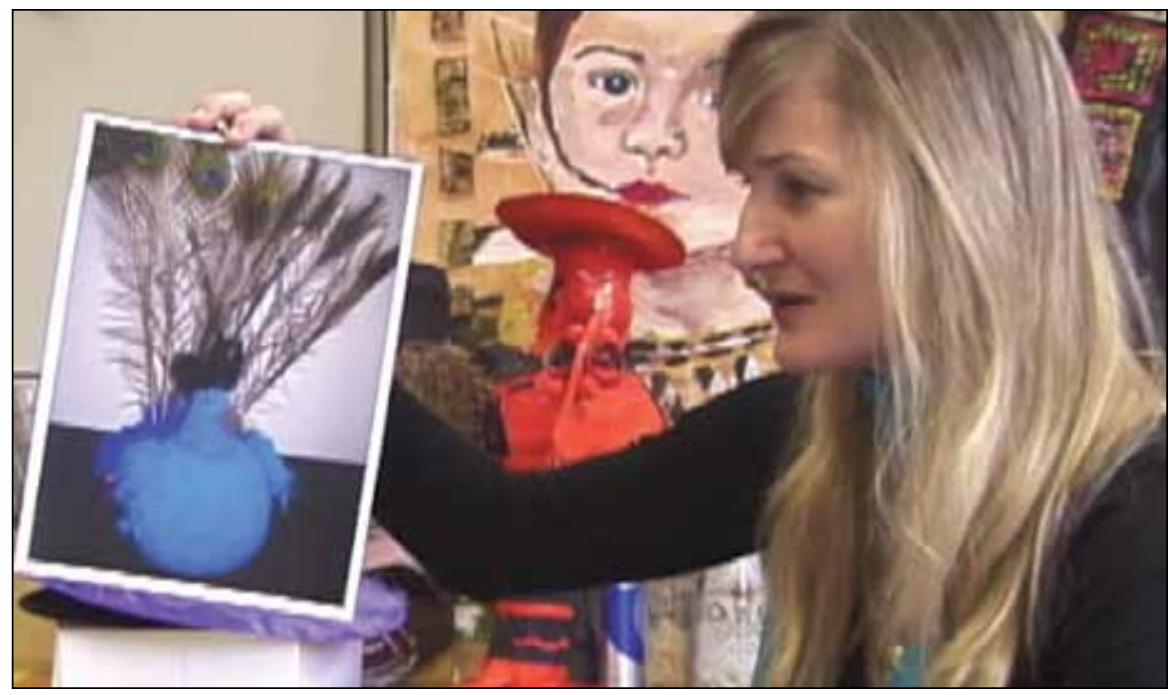

Fig. 1: Grade three pumpkin transformation project by Milo Berger and Grace Lipovetz 
This is a project that the grade three class recently undertook and it was a transformation project. In fact, what you're seeing here is a pumpkin. I asked the students to look at the round shape and to transform it in some way. They worked collaboratively in groups of two and they created these pumpkin transformations. They built whatever it is that they needed to build - it was an additive sculpture. They weren't allowed to cut away because the pumpkins decompose too quickly otherwise. The whole creative process was really made explicit in this project. We looked at generating a lot of ideas and then choosing the one that was the best. And if they chose to come together with a partner they had to collaborate and as a team decide which ideas would best work together and which ideas they would have to leave behind. At times they would try things in terms of construction that didn't work. They had to resolve the problems. They had to figure out what materials they needed, how they were going to adhere the things that they had prepared to the pumpkins themselves. One of the students summed it up best and said, "We're really good at solving these problems, aren't we?" [laughter]. That was essentially what the project was trying to address: the idea of the creative process and the problem solving that goes along the way. My role: I did some shopping for supplies and I was also the head "hot glue" person but they took full ownership and the results were extraordinary.

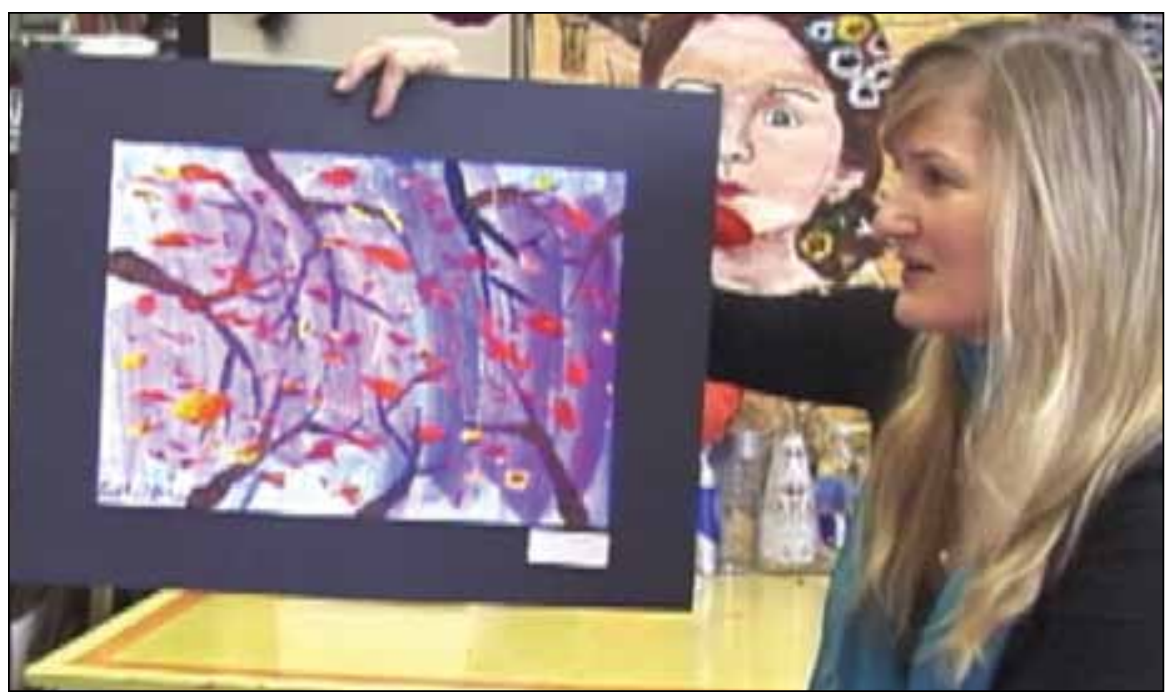

Fig. 2: Grade one art project by Lorelai 
This one is an example of children in grade one. In grade one the question is, "Where do the ideas come from? Where do artists get their ideas?"We look at art ideas as coming from your imagination. We look art ideas as a representation of naturewe go outside and we draw the sunflowers that are in the back parking lot. And then we look at art ideas as observation from a different perspective. We all went out and lay under the trees and looked at the trees right up through the sky and then the students painted what it is that they saw. They also look at art as a marriage between the imagination and observation.

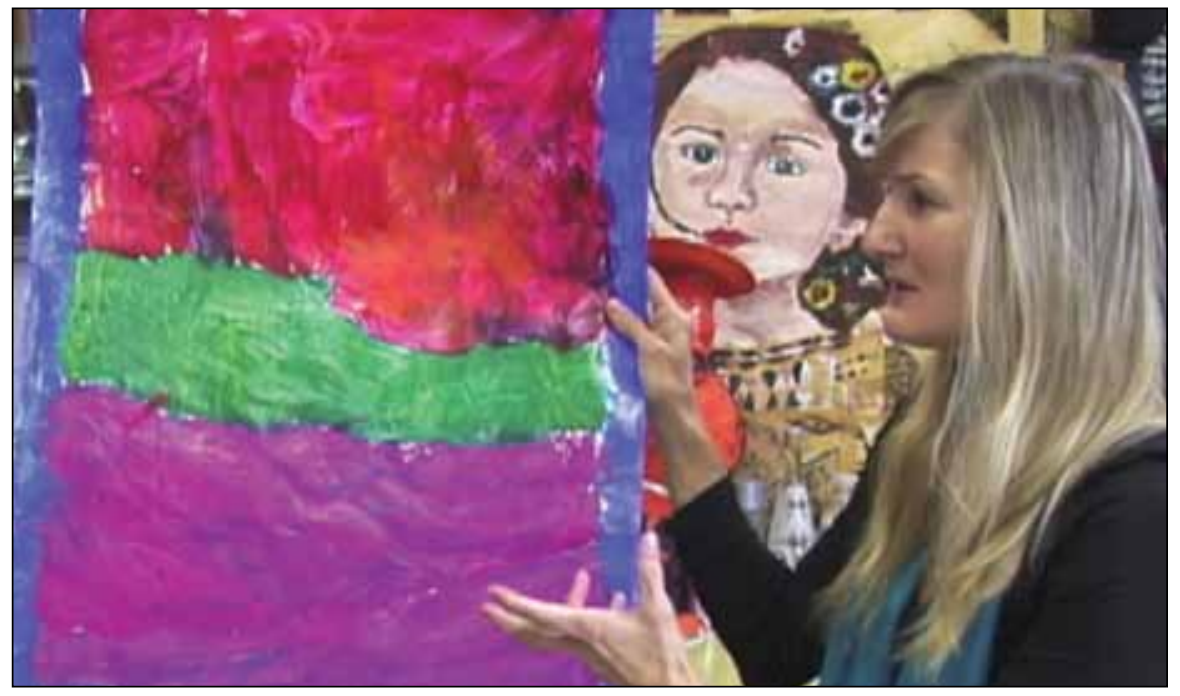

Fig. 3: Exploratory piece of students learning to speak "Mark Rothko" by Anika (Grade 2)

This is an exploratory piece so it's not a final project-it would be an interim project. I would give the students an opportunity to look at the work of Mark Rothko. For example, we would discuss his style and then we would attempt to speak "Mark Rothko" because I often talk to the students of art as a language. So they learn to speak English and they learn to speak French and here they learn to speak "Mark Rothko." And using Rothko's language they try to create a portrait of something or someone that was important to them. They made choices in terms of colour, they made choice in terms of the materials and the tools that they would use, and they would play with texture. From that, their final piece would be an attempt to create their own language because ideally what I want them to do is not just to imitate someone else-I want them to create and find their own creative voice so that they can talk about the world around them. This is an interim piece; a final piece has yet to come. In it, they're using colour and shape and figurative work or abstract-as they see fit-to best express the world that they see around them. 


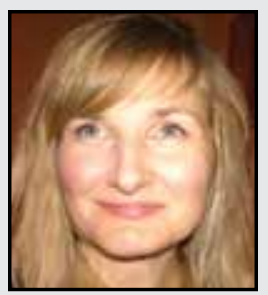

Zenia Dusaniwsky is currently working as an Art Specialist at St. George's Elementary School in Montreal, but has 22 years of varied teaching experience behind her. She has taught at different grade levels ranging from Pre-K to University and in different subject areas including: Science, Math, Language Arts, Social Studies, and Art. Her experiences have taken her overseas where she taught in established International School settings as well as in shantytowns and remote jungle communities. Zenia has a B.Ed., a Certificate in the Teaching of Arts, as well as an M.Ed. in Educational Psychology and Counseling.

\section{LINKTO:}

http://www.theartstory.org/artist-rothko-mark.htm 